\title{
AC 2010-2213: INTEGRATING SYSTEMS ENGINEERING IN MAIN STREAM ENGINEERING DISCIPLINES
}

\section{Satinderpaul Devgan, Tennessee State University}

Dr. Satinderpaul Singh Devgan is Professor and Head of Electrical and Computer Engineering at Tennessee State University since 1979. He received his M.S. and Ph.D. degrees in Power Systems from Illinois Institute of Technology before joining Tennessee State University in 1970. He has developed and implemented new M.S. and Ph.D. in Computer and Information Systems Engineering (CISE) programs, and has published in IEEE and ASEE Conference Proceedings. He is a recipient of Outstanding Researcher of the Year award in 1994 from Tennessee State University and was inducted to its Million Dollar Research Club. He has served as Secretary/Treasurer, Vice-Chairman and Chairman of the ECE Division of ASEE and now serves as an IEEE ABET Evaluator. He is a Life Senior Member of IEEE and ASEE, a member of Eta Kappa Nu and Phi Kappa Phi Honor Societies and is a Registered Professional Engineer in Tennessee. He is past-chairman of Southeastern Association of Electrical Engineering Department Heads (SAEEDH) and is currently serving as Secretary of the BOD of Southeastern Center for Electrical Engineering Education (SCEEE). He also served as Editor of ECEDHA Newsletter from 2001 to 2006.

\section{Sachin Shetty, Tennessee State University}

Dr. Sachin Shetty received the B.S. degree in Computer Engineering from Mumbai University, Mumbai,India in 1998, M.S. in Computer Science from University of Toledo in 2002, and Ph.D. degree in Modeling and Simulation from Old Dominion University in 2007. He is currently an Assistant Professor in the Department of Electrical \& Computer Engineering at TSU. His research interests are in the design and performance analysis of mobile adhoc networks and wireless sensor networks, dynamic spectrum access in cognitive radio networks, and wireless network security. Recently, he is investigating control theoretic and machine learning based techniques to perform anomaly based intrusion detection. He has published extensively in various peer-reviewed conferences, journals and book chapters and has over 25 publications in research and pedagogical techniques.

\section{Saleh Zein-Sabatto, Tennessee State University}

Dr. M. Saleh Zein-Sabatto is a Professor and a graduate faculty in the Department of Electrical and Computer Engineering since 1991. He received his B.S. degree in Power Systems from the University of Aleppo, Syria in 1979, and the M.S. and Ph.D. degrees in Electrical Engineering from Vanderbilt University, Nashville, Tennessee in 1986 and 1990, respectively. Dr.

Zein-Sabatto has a strong commitment to teaching and research. His area of competency includes teaching and conducting theoretical and experimental research in: artificial intelligence; intelligent control, reconfigurable and distribute control systems; systems diagnostics and prognostics; mobile robotics; sensor fusion and layered systems; and engineering systems design. $\mathrm{He}$ is a Senior Member of IEEE and a member of Eta Kappa Nu Honor Societies. He has received numerous recognitions and awards. He is a recipient of NASA's award for creative development of a technical innovation in June 1993. 


\title{
INTEGRATING SYSTEMS ENGINEERING IN MAIN STREAM ENGINEERING DISCIPLINES
}

\begin{abstract}
Systems Engineering is a life cycle engineering approach that is being used for development of large systems. It has been implemented by DoD, NASA, and most all major corporations such as Lockheed Martin, Boeing, Northrop Grumman, Raytheon, etc. There are over 120 programs in systems engineering that are currently being offered at the undergraduate and graduate levels [1]. A large percentage of these are graduate programs or certificate programs in Systems Engineering and are mostly housed in industrial and systems engineering departments. Yet there are only a handful of undergraduate programs offered by universities that integrate systems engineering in main stream engineering disciplines such as electrical engineering, mechanical engineering, etc. A systems engineering based concept curriculum, that provides foundation for a broad-based major discipline such as electrical engineering, is presented. This is proposed as a domain centric systems engineering program under the Bachelor of Science in Electrical Engineering program. The motivation to develop such a program stems from the growing industry demand for systems engineers who are equipped with skills related to development, evolution and verification of life-cycle based system solutions for a variety of applications in the areas of power and energy, telecommunications and information technology, robotics and control systems, and hardware and software-based embedded systems.
\end{abstract}

\section{Introduction}

Classical engineering has largely focused on product performance. As systems become more complex, high performance based product designs may not lead to high performance systems of which the product is a part. Recent experiences indicate that a systemic approach (consideration of the whole rather than piecemeal) or life cycle engineering during the early stage of system definition, design, and development, is essential for global competition [2]. Most systems today are quite complex. A systems engineering (SE) (life cycle engineering) approach is needed to be competitive. Further it is important that discipline content engineering specialists be familiar with the structure function and purpose of systems engineering [3].

It is evident that most of the national resources will be directed towards development of national critical technologies. National critical technologies are defined as technologies that are so fundamental to national security or so highly enabling the economic growth that the capability to produce these technologies must be retained or developed in the United States. The requirement for National Critical Technologies report was established under the 1990 Defense Appropriations Act and the list of technologies was increased from the original six (6) in the 1991 report to seven (7) in 1995. These critical technologies include (1) Materials, (2) Manufacturing, (3) Information and Communications, (4) Transportation, (5) Living Systems, (6) Energy and (7) Environmental Quality [4]. So continuous improvements in education at all levels are considered essential to the future economic prosperity and national security of the United States. 
Most new growth and work force increases will occur in the related technology areas. Solutions to these critical technologies will involve definition, development and implementation of complex and multidisciplinary systems. These will require engineers and scientists with training and experiences in systems engineering approach.

\section{Need Analysis}

Because of global competition, products and systems have to deliver more and are becoming more complex. Engineers of the future must be trained in systems engineering approach rather than classical engineering design approach. Further most systems of the future will use information (signal, communication in analog and digital form), computers (hardware, software, and firmware) and broad-based engineering technologies.

Table 1

Employment Projections at Local, State and National Level $[5,6]$

\begin{tabular}{|l|l|l|l|l|l|l|l|l|l|l|}
\hline & \multicolumn{3}{|c|}{ Local [5] } & \multicolumn{3}{c|}{ State [5] } & \multicolumn{3}{c|}{ National [6] } \\
\hline Title & 2006 & 2016 & $\begin{array}{l}\text { percent } \\
\text { overall } \\
\text { growth }\end{array}$ & 2006 & 2016 & $\begin{array}{l}\text { percent } \\
\text { overall } \\
\text { growth }\end{array}$ & 2008 & 2018 & $\begin{array}{l}\text { percent } \\
\text { overall } \\
\text { growth }\end{array}$ \\
\hline $\begin{array}{l}\text { Computer and Mathematical } \\
\text { Occupations 15-0000 }\end{array}$ & 11680 & 14320 & $22.6 \%$ & 39650 & 47870 & $20.7 \%$ & $3540 \mathrm{~K}$ & $4326 \mathrm{~K}$ & $22.2 \%$ \\
\hline $\begin{array}{l}\text { Computer Software } \\
\text { Engineers, Applications } \\
15-1031\end{array}$ & 1260 & 1760 & $39.9 \%$ & 2820 & 3980 & $41.1 \%$ & $514.8 \mathrm{~K}$ & $689.9 \mathrm{~K}$ & $34 \%$ \\
\hline $\begin{array}{l}\text { Computer Software } \\
\text { Engineers, Systems } \\
\text { Software 15-1032 }\end{array}$ & 790 & 990 & $25.1 \%$ & 2640 & 3620 & $37.1 \%$ & $394.8 \mathrm{~K}$ & $515 \mathrm{~K}$ & $30.4 \%$ \\
\hline $\begin{array}{l}\text { Database Administrators } \\
15-1061\end{array}$ & 420 & 530 & $24.6 \%$ & 1120 & 1420 & $26.8 \%$ & $120.4 \mathrm{~K}$ & $144.7 \mathrm{~K}$ & $20.3 \%$ \\
\hline $\begin{array}{l}\text { Network and Computer } \\
\text { Systems Administrators } \\
15-1071\end{array}$ & 1150 & 1530 & $33.5 \%$ & 4190 & 5510 & $31.5 \%$ & $339.5 \mathrm{~K}$ & $418.4 \mathrm{~K}$ & $23.2 \%$ \\
\hline $\begin{array}{l}\text { Network Systems and Data } \\
\text { Communications Analyst } \\
15-1081\end{array}$ & 980 & 1330 & $36.1 \%$ & 2590 & 3990 & $54.1 \%$ & $292.0 \mathrm{~K}$ & $447.8 \mathrm{~K}$ & $53.4 \%$ \\
\hline $\begin{array}{l}\text { Architecture and } \\
\text { Engineering } \\
\text { Occupations 17-0000 }\end{array}$ & 9600 & 10220 & $6.4 \%$ & 37300 & 39860 & $6.86 \%$ & $2636 \mathrm{~K}$ & $2906.6 \mathrm{k}$ & $10.3 \%$ \\
\hline $\begin{array}{l}\text { Electrical Engineers } \\
17-2061,-2071,-2072\end{array}$ & 1610 & 1820 & $13.0 \%$ & 3630 & 4020 & $10.7 \%$ & $376.2 \mathrm{~K}$ & $382.1 \mathrm{~K}$ & $1.57 \%$ \\
\hline
\end{tabular}

Table 1 provides the local, state and national demand for electrical, computer and systems engineering related professionals from 2008-2018. As is clear from this table, the projected demand for traditional engineering disciplines, such as architecture, civil, electrical and mechanical, is very low as compared to that for computer software engineers. This demand is even higher (54.1\%) for network systems and data communication analysts (systems engineers). These demands are related to critical technology areas of information and communication. As national attention is being directed to address growing energy demand and environmental quality 
concerns, increased demand for power engineers with network communication experience is expected soon. Further about $40 \%$ of current electric power systems engineers will retire in another ten years and the demand will increase even more in this area. These trends indicate that a change in education and training of future engineers is needed. This paper attempts to present an approach to replace engineering design layer within an engineering curriculum, with a systems engineering design layer. It is our premise that "You cannot train experience. However you can educate and train system analysts and engineers in system analysis, design and development" [7].

The identified areas with significant demand require background and training in systems engineering along with broad-based electrical engineering curriculum in communication systems, power systems, robotics, control systems, and computer software and hardware systems. Critical technology areas related to electrical engineering are information and communication, and energy. Development of these critical technologies will require systems engineering background besides traditional, broad-based electrical engineering foundation in electronics, signals and communication systems, power and control systems, and computer communication networks.

\section{What is Systems Engineering?}

Systems engineering is also called life cycle engineering or consideration of system requirements and performance from birth to its death or disposal. Figure 1 is a graphically representation of systems engineering process. It involves conceptual design phase, where system requirements are developed in consultation with the stake holders, long range plan for system development, manufacture, support services and training needs and system engineering management plan are developed. This is the most important phase where about $60 \%$ of the project resources are committed. During the preliminary design (top-down) phase, the overall system is broken down to lowest possible level or component level and requirements are allocated to each component. Next during the detailed design (bottom-up) phase, subsystems are designed, tested and integrated to the whole system level. The developed system is then constructed and manufactured. Long range planning must provide support for system development and the manufacturing facilities. The operational phase involves the use of the developed system with logistics, maintainability, supportability, reliability and support for upgrade of the system during its lifetime until retirement.

Curriculum content to address Systems Engineering (SE) skill requirements should include following topic areas;

- Introductory and advanced system engineering

- system architecting and systems analysis

- modeling and simulation, model testing

- Reliability, Maintainability and availability

- Requirements definition, analysis and configuration management

- Human Systems Integration

- Life cycle engineering and life cycle cost analysis 


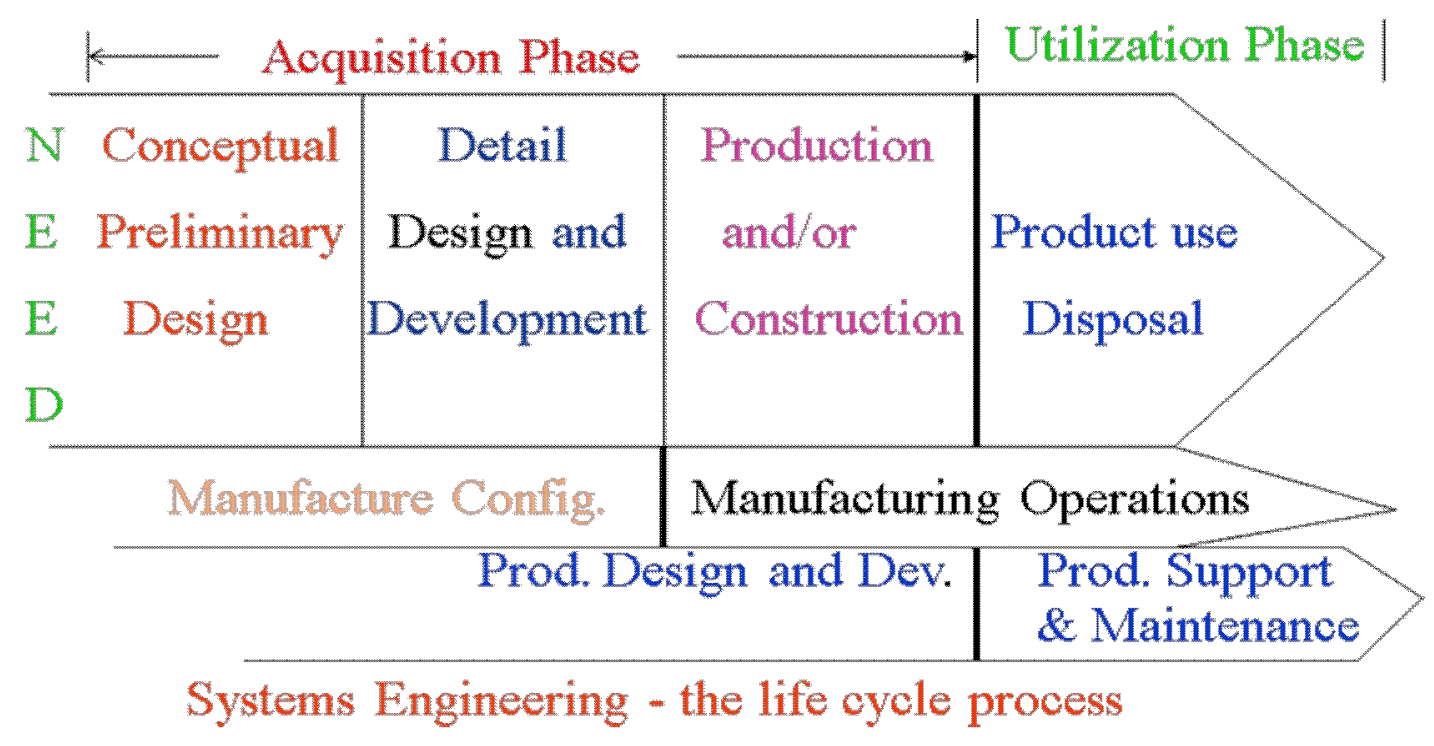

Figure 1. Systems Engineering Process [2]

To graduate competent electrical engineers with systems engineering skill sets, the educational (BSEE) programs should emphasize "systems thinking" throughout the curriculum. "Systems thinking" is the ability to always keep the ultimate objectives in mind throughout the design process and make the decisions to stay on track. This must occur throughout the requirements, the design, the production and deployment phases.

\section{Survey of Systems Engineering Programs}

There are about 75 US universities that offer about 120 SE programs. Most (88) of these programs are offered at the graduate level (MS). There are about $43 \mathrm{SE}$ programs offered at the undergraduate level. Most major defense companies have established their own SE development programs in order to prepare their employees with the necessary skills. References 1 and 2 have done an extensive analysis of existing programs and reference 2 has developed guidelines for development of graduate programs in systems engineering [1,2]. Majority of the program are in Industrial and Systems Engineering and a few in Biosystems and Agricultural Engineering. To our knowledge there are no programs that offer discipline centric systems engineering integrated BSEE degree programs.

\section{Proposed Curriculum for Systems Engineering integrated BSEE Program}

This proposed curriculum, as shown in Table 2, builds upon a foundation in mathematics, basic and engineering sciences, leading to a systems engineering integrated broad-based undergraduate curriculum in Electrical Engineering. The systems engineering courses replaces the traditional Introduction to Design course and provides a systems engineering-based foundation for upper level electrical engineering and capstone design courses. The program provides fundamental background in some of the critical technology areas and high demand technical areas related to 
electrical engineering such as information and communication, and energy. The curriculum also addresses most of the areas identified above as necessary for a systems engineering background.

Table 2

Curriculum for System Engineering Integrated B.S. E.E. Degree Program

\begin{tabular}{|c|c|c|c|c|c|}
\hline & Fall Semester & $\mathrm{Cr}$ & & Spring Semester & $\mathrm{Cr}$ \\
\hline ENGL 1010 & Freshman English I & 3 & ENGL 1020 & Freshman English II & 3 \\
\hline MATH 1910 & Calculus I, Alternate & 4 & MATH 1920 & Calculus II, Alternate & 4 \\
\hline CHEM 1110 & General Chemistry & 3 & PHYS 2110 & General Physics I & 3 \\
\hline CHEM 1111 & General Chemistry Lab & 1 & PHYS & General Physics I Lab & 1 \\
\hline ECSE 1010 & Computer Engineering Tools & 3 & HIST & American History I & 3 \\
\hline $\begin{array}{ll}\text { ENGR } 1000 \\
\end{array}$ & Engineering Orientation & 1 & ENGR & Comp. Prog.For Engineers & 3 \\
\hline Total & & 15 & Total & & 17 \\
\hline
\end{tabular}

\begin{tabular}{|c|c|c|c|c|c|}
\hline & Fall Semester & $\mathrm{Cr}$ & & Spring Semester & $\mathrm{Cr}$ \\
\hline MATH 2110 & Calculus III, Alternate & 4 & MATH 3120 & Applied Mathematics & 3 \\
\hline PHYS 2120 & General Physics II & 3 & ENGR 2000 & Circuits I & 3 \\
\hline $\begin{array}{ll}\text { PHYS } 2121 \\
\end{array}$ & General Physics II Lab & 1 & ENGR & Circuits I Lab & 1 \\
\hline ENGR 2140 & Comb.Statics \& Dynamics & 3 & ENGR & Transport Phenomena & 3 \\
\hline COMM 2200 & Public Speaking & 3 & ENGR & Numerical Analysis & 3 \\
\hline HIST 2020 & American History II & 3 & $\begin{array}{ll}\text { ENGL } & 2110 \\
\text { or 2310 } & \end{array}$ & $\begin{array}{l}\text { American or World } \\
\text { Literature I }\end{array}$ & 3 \\
\hline Total & & 17 & Total & & 16 \\
\hline
\end{tabular}

All students are required to take and pass the Engineering Entrance Examination (EEE) prior to enrolling in upper level (3000-4000) major and engineering courses.

\begin{tabular}{|c|c|c|c|c|c|}
\hline & Fall Semester & $\mathrm{Cr}$ & & Spring Semester & $\mathrm{Cr}$ \\
\hline EECE 2120 & Circuits II & 3 & EECE 3200 & Linear Systems & 3 \\
\hline EECE 3100 & Design of Digital Logic Systems & 3 & EECE 3300 & Electronics & 3 \\
\hline EECE 3101 & Design of Digital Logic Syst. Lab & 1 & EECE 3301 & Electronics Lab & 1 \\
\hline ECSE 3200 & Intro to Systems Engineering & 3 & ECSE 3400 & Disc. Event Sys Mod.Simul. & 3 \\
\hline ENGR 3300 & Materials Science & 3 & & Humanities Elective & 3 \\
\hline ECSE 4400 & $\begin{array}{l}\text { Probability, Statistics and Risk } \\
\text { Analysis }\end{array}$ & 3 & EECE 3210 & Electromagnetic Theory & 3 \\
\hline Total & & 16 & Total & & 16 \\
\hline
\end{tabular}

\begin{tabular}{|cc|l|c|l|l|c|}
\hline & \multicolumn{1}{|c|}{ Fall Semester } & Cr & & \multicolumn{1}{|c|}{ Spring Semester } & Cr \\
\hline ENGR & 4500 & Capstone Design Project I** & $\mathbf{1}$ & ENGR 4510 & Capstone Design Project II* & $\mathbf{1}$ \\
\hline EECE 4000 & Control Systems & $\mathbf{3}$ & & Humanities Elective & $\mathbf{3}$ \\
\hline ECSE & 4600 & System Engineering Analysis & 3 & EECE 3420 & Power Systems & $\mathbf{3}$ \\
\hline EECE & 3500 & Communication Systems & $\mathbf{3}$ & ENGR 4900 & Prof. Develop. Seminar & $\mathbf{1}$ \\
\hline ENGR 4201 & Engineer-in-Training Lab (3), & $\mathbf{0}$ & & Technical Electives (1) & $\mathbf{3}$ \\
\hline EECE 4101 & Electrical Systems Design Lab & $\mathbf{1}$ & & Social Science Electives (2) & $\mathbf{3}$ \\
\hline & Social Science Electives (2) & $\mathbf{3}$ & & & \\
\hline EECE 4310 & Software Engineering & $\mathbf{3}$ & & & \\
\hline \multicolumn{2}{|c|}{ Total } & & $\mathbf{1 7}$ & Total & & $\mathbf{1 4}$ \\
\hline
\end{tabular}

The major changes are the replacement of Introduction to Engineering and Engineering Graphics and Design courses with an ECSE 1010 Computer Engineering Tools course at the Freshman level. During the Sophomore year, Statics and Dynamics courses are replaced by a combined Statics/Dynamics course. During the Junior Year, ECSE 3200 Introduction to Systems Engineering replace Introduction to Engineering Design course and Discrete Event System Simulation replaces a technical elective course. The existing Probability and Statics course is 
modified to Probability, Statics and Risk Analysis course. Discrete Event and Continuous System simulations is included to provide background and training in systems modeling. Systems Engineering Analysis replaces Energy Conversion course in the senior year. Communication System, Software Systems Engineering, Control Systems and Power Systems are the senior level courses that provide systems engineering based design experiences that lead to $100 \%$ systems engineering based Electrical Systems Engineering Design Laboratory and a two sequence Capstone Design experience that will incorporate systems engineering (life cycle) design process. Course descriptions for new courses are provided to show how skill sets are developed through course outcomes. The new required and technical electives in the systems engineering concentration are in italic font and provide the necessary background and skills identified earlier. The Program Outcomes for the BSEE program are all covered by the existing and new courses and the updated curriculum meets the ABET Program Criterion.

\section{System Engineering Skillsets}

It takes between 10 to 15 years of hands-on experience before the typical systems engineer can perform in a lead role. The minimum systems engineering skill sets as required of program graduates are covered in courses listed next to the skill:

1) Principles of Systems Engineering - ECSE 1010, ECSE 3200, ECSE 4600

2) Electrical Engineering - ENGR 2000, EECE 2120, 3200, 3210, 3100, 3101, 3300, 3301, EECE 3420, 4000, 4101, etc

3) Software engineering - EECE 4310

4) Reliability, Availability, Maintainability - ECSE 4400, ECSE 4600. ENGR 4500, 4501

5) Logistics support - ECSE 4600

6) System Design and Architecture, System Integration - ECSE 3200, 4600, EECE 4101, ENGR 4500,

7) Risk Analysis \& Management - EECE 4400

8) Requirements Definition, Analysis, Management - ECSE 3200, 4600

9) Lifecycle systems engineering - ECSE 4600, ENGR 4500, 4501

10) Manufacturing \& Producibility - ECSE 4600

\section{Program Outcomes}

These outcomes are consistent with the aforementioned skillsets and the mission of our Electrical Engineering Program. All graduates of the Electrical Engineering program are expected to have:

a. an ability to systematically apply knowledge of mathematics, science and engineering sciences to solve problems (ABET Criterion 3.a, Program Criteria).

b. an ability to plan, design, and conduct engineering experiments as well as to analyze and interpret data and report results (ABET Criterion 3.b).

c. an ability to systematically identify, formulate, design and demonstrate electrical engineering systems, subsystems, components and/or processes that meet desired performance, cost, time and safety requirements (ABET Criterion 3.c and program criterion).

d. an ability to function on multidisciplinary teams (ABET Criterion 3.d). 
e. an ability to identify, formulate and solve engineering and electrical engineering problems (ABET Criterion 3.e, Program Criteria).

f. an understanding of professional and ethical responsibility (ABET Criterion 3.f).

g. an ability to communicate technical information through professional quality reports, oral presentations and interaction with audience (ABET Criterion 3.g).

$\mathrm{h}$. the broad education necessary to understand the impact of electrical engineering solutions in a global and societal context (ABET Criterion 3.h).

i. a recognition of the need for and an ability to engage in life-long learning (ABET Criterion 3.i).

j. a knowledge of contemporary issues (ABET Criterion 3.j).

k. an ability to use modern techniques, skills and tools including computer based tools for analysis and design (ABET Criterion 3.k).

1. Knowledge of probability and statistics, numerical analysis and their applications. (program criterion).

m. familiarity with appropriate Codes and Standards.

We can add other outcomes or modify these to meet the needs of systems engineering program. We already have established procedures and processes to measure and evaluate the results for continuous improvement. These same processes will be used to assess the success in achieving Program Outcomes and Program Education Objectives of the Systems Engineering integrated BSEE curriculum.

\section{New Courses Being Developed}

ECSE 1010 Computer Engineering Tools (3): This course will expose the students to key hardware and software technologies required to become competent Systems Engineers. The hardware skills are exposure to Oscilloscopes, Digital Multimeters, Function Generators and microcontrollers. The software skills will include exposure to Matlab, Simulink, Labview, and PSPICE.

ENGR 2140 Combined Statics and Dynamics (3): Statics of particles; statics of rigid bodies in three dimensions; cancroids and centers of gravity; friction and moment of inertia. Study of the kinematics and kinematics of particles and rigid bodies; Principle of work and energy; Principle of impulse and momentum. Prerequisite: Math 2110, Physics 2120.

ECSE 3200 Introduction to Systems Engineering (3): This course will introduce students to the fundamental principles of systems engineering and its application to the development of complex systems. Engineering of complex hardware, software systems encompasses quantitative methods to understand vague problem statements, determine what a proposed product/system must do (functionality), generate measurable requirements, decide how to select the most appropriate solution design, integrate the hardware and software subsystems and test the finished product to verify that it satisfies the documented requirements. Topics include requirements analysis, concept definition, system synthesis, design tradeoffs, risk assessment, interface definition, engineering design, system integration, and related systems engineering activities, including project management and life cycle cost analysis. Prerequisite: Math 3120, Co-Requisite ECSE $4400[5]$. 
ECSE 3400 Discrete Event System Modeling and Simulation (3): This course introduces the discrete event systems simulation process and the probability and statistics basic knowledge used in simulation studies, simulation examples statistical models for queuing, inventory and supply chain, reliability models, discrete and continuous simulation, random variate generators, acceptance-rejection techniques, input modeling, verification, calibration and validation of simulation model, evaluation of absolute performance and relative performance. Prerequisite: ECSE 4400.

ECSE 4400 Probability, Statistics and Risk Analysis (3): This course will build upon the fundamentals of probability of failure, failure mode analysis, and reliability and maintainability. Topics include methods to analyze and quantify the risk of failures, and the reliability of complex systems, including fault tree analysis, and reliability block diagrams. The allocation of reliability and maintainability requirements to subsystems to component level. It will also cover Failure Mode Criticality Analysis. Pre-requisite: ENGR 4400, ECSE 4600.

ECSE 4600 Systems Engineering Analysis (3): This course provides the conceptual and analytic basis for a new approach to design: the use of evaluation function to optimize the financial value or performance of the System. Topics include theory and models for decision making under uncertainty, multiple criteria, economic evaluation, design optimization, project and process control, considerations of reliability, maintainability, producability, usability, support and affordability. Three hours lecture. Prerequisite: ECSE 3200 [5].

\section{Assessment Tools}

Outcomes will be identified for each course. Existing evaluation processes for analysis, evaluation and continuous improvement will be reviewed, updated if needed, used and implemented. The existing process includes surveys and direct measures and included internal and external assessments as identified below. All of these processes and documents have been approved by the program faculty and advisory committee and the department head.

Internal Assessment

Internal assessment tools include Senior Exit Survey, Student Course Assessment Survey, Departmental Accreditation Committee's overall assessment of Faculty Course Outcomes Assessment Reports, and Capstone Design Project I and II Issues and Written Reports. The last two are direct measures.

\section{Senior Exit Survey}

Graduating senior's assessment of the level of accomplishment of the Program Outcomes is carried out through the Senior Exit Survey. One part of this survey is designed to evaluate the level of achievement of the Program Outcomes. This survey is conducted and collected every semester by the departmental Administrative Assistant during the final week of the student's graduation semester. The survey is summarized and analyzed by the Departmental Accreditation 
Committee. It is also reviewed by the department head. The survey data is filed and maintained by the departmental Administrative Assistant but the summary results are maintained by the department head. A criterion for successful accomplishment of each outcome is an average score of 3.0 or better out of 4.0 .

\section{Student Course Assessment Survey}

This survey is unique for each course and is used to seek student input in determining the level of achievement of each of the individual Program Outcomes covered by the given course. This survey is conducted and collected, during the last two weeks of the semester, every time the course is offered, by the departmental Administrative Assistant. The survey is summarized and analyzed by the Departmental Accreditation Committee and reviewed by the department head. The survey data is filed and maintained by the departmental Administrative Assistant but the summary results are maintained by the department head and a copy is given to the instructor of the course. A criterion for successful accomplishment of each outcome is an average score of 3.0 or better out of 4.0 from a culmination of contributions from all courses.

\section{Faculty Course Outcomes Assessment Report (Direct Measure)}

The faculty input is the most important of all assessments because it uses all the tools for course assessment. Each faculty member prepares modules to assess accomplishment of course and program outcomes. These modules may include homework assignments, tests and reports to measure success in achievement of a related outcome. This is a quantitative measure of achievement of an outcome. Faculty Course Outcomes Assessment Report describes specific recommendations on course objectives and course outcomes, content and evaluation. This report includes qualitative assessment of each applicable Program Outcome, recommendations for its improvement, and implementation steps. Faculty is also involved in the final decisions on recommendations from the Departmental Accreditation Committee, the Departmental Curriculum Committee and feedback from College, University Administration, and Supporting Programs wherever applicable. This report is due within two to three weeks from the end of the semester the course is offered. The criterion for successful achievement of the Program Outcomes is the cumulative quantitative assessment of the various Faculty Course Outcomes Assessment Reports for each outcome.

\section{Capstone Design Project I and II Reports (Direct Measure)}

The Capstone Design Project I and II is a culminating culminating systems design experience for each graduating student. It includes project issues reports, engineering design, and establishment of milestones, meeting established deadlines, and written technical report. This covers the Program Outcomes ' $\mathrm{a}, \mathrm{c}, \mathrm{e}, \mathrm{f}, \mathrm{h}, \mathrm{i}, \mathrm{j}, \mathrm{k}, \mathrm{l}$ and $\mathrm{m}$. The assessment tool is the completed Capstone Design Project I and II Check List Sheet prepared by the course instructors. The tool was approved by the College Administrative Council and in maintained by the course instructor. Criteria for successful accomplishment of each Program Outcome mentioned above is a grade of $\mathrm{C}+$ (or 3.0 or better out of 4.0 , or $75 \%$ ) in each of the Program Outcomes as determined by the course instructor with input from project advisor. 


\section{External Assessment}

External assessment includes input from Alumni Survey, Employer Survey (by recruiter, or alumni), Evaluation of Capstone Oral Presentation by Cluster, and Advisory Committee/Cluster Input (based upon observation of student capstone design presentations and program review).

\section{Alumni Survey}

The Alumni Survey of the graduates of the past five years will be conducted, every two years, by the departmental Administrative Assistant. The Alumni Survey assesses the level of the accomplishment of the Program Educational Objectives, the Program Outcomes and other educational experiences.

The Alumni Survey is sent, collected, filed and maintained by the departmental Administrative Assistant. It is reviewed, summarized and analyzed by the Departmental Accreditation Committee/Department Head (with assistance from a graduate assistant) and the results are submitted to the department head for record keeping. A criterion for success in each Program Outcomes is an average score of 3.0 or better out of 4.0 in each outcome.

\section{Employer Survey}

It is designed to seek employer input on the level of satisfaction of Program Educational Objectives and the Program Outcomes based upon their experience with graduates of our program, and other services offered by the university for employers of our graduates. Every two years, the employers of our graduates are surveyed using the Employer Survey Form. This survey is conducted, collected, filed and maintained by the departmental Administrative Assistant. It is analyzed, documented and reported by the Departmental Accreditation Committee and sent to the department head for record keeping and for use to assess accomplishments. The criterion for success in each achieving Program Outcome is an average score of 3.0 or better out of 4.0 .

Evaluation of Capstone Oral Presentation by Cluster (direct measure)

Every year in April and November, Industrial Cluster members and engineers from local industry are invited to review our senior student Capstone Design Project II Oral Presentations of their projects. Criteria for satisfactory achievement of these outcomes is a 2.25 out of 3.0.

\section{ECE Advisory Committee/Cluster Input}

Twice a year, Industrial Cluster members visit the campus to review our student Capstone Design Project presentations. During the second day of their visit they review our program offerings and provide valuable input toward accomplishments of program educational objectives and other curriculum matters. This input is in the form of verbal and written recommendations by the cluster to the Dean and/or the Department Head. This information is collected and reviewed 
regularly and is used in assessment as external input. Same criteria are used for this assessment also.

\section{Conclusions}

A number of employers have hired our graduates from our Master of Science in Computer and Information Systems Engineering program which has been quite popular. Graduates with Systems Engineering background will become more valuable with years of experience. Because of shortage of experienced systems analysts and system integrators, the graduates from such programs will be in great demand and command higher salaries. We believe the demand for engineers with background in systems engineering will be in even more as the systems become more complex and critical technologies in energy and environmental quality are developed.

\section{References}

1. Fabrycky, W. J. and McCrae, E.A. (2005) "Systems engineering degree programs in the united states." In Proceedings of the 15th Annual International Symposium, INCOSE 2005, Rochester, NY, USA, July 1015, 2005.

2. B. S. Blanchard, W. J. Fabrycky, Systems Engineering and Analysis. Prentice Hall, 4th. Ed. 2006.

3. Andrew P. Sage, "The role of systems engineering in electrical engineering." IEEE Transactions on Education. Vol. E-22, May 1979, pp: 81-85.

4. Appendix A: National Critical Technologies List. http://clinton1.nara.gov/White House/EOP/OSTP/CTIformatted/AppA/appa.hmtl. Jan. 28, 2008.

5. http://thesource.tnvi.net labor and workforce analysis 2006-2016. Accessed Jan. 6, 2010

6. Electrical and Systems Engineering http://www.ese.upenn/ugrad/minor.html. Accessed Jam. 7, 2010.

7. Wasson C. S. System Analysis, Design and Development concepts, principles and practices. John Wiley, 2005.

8. http://www.bls.gov/oco/oco.htm. Accessed Jan. 8, 2010. 